ISSN : 2776-8740 (Online-Elektronik)

\title{
Orchidftgri
}

Vol. 1, No. 1, Bulan Februari Tahun 2021

DOI: http://dx.doi.org/10.35138/orchidagri.v1.i1.257

\section{Analisis Pendapatan Dan Efisiensi Usahatani Padi Varietas Ciherang (Studi Kasus pada Kelompok Tani Wargi Saluyu di Desa Ciparay, Kecamatan Ciparay, Kabupaten Bandung)}

\author{
Farid Abdul Haris, Nataliningsih, Nendah Siti Permana \\ Program Studi Agribisnis Fakultas Pertanian \\ Universitas Winaya Mukti \\ Jl. Raya Bandung-Sumedang Km. 29 Tanjungsari Sumedang \\ Email: faridabdulharis48@gmail.com
}

(Received: 04-01-21; Published: 20-02-21)

\begin{abstract}
This research was conducted to analyze the level of income and efficiency of rice farming in the Wargi Saluyu farmer group, Ciparay Village. The rice varieties that are the focus of this research are the Ciherang variety. The method used in this research is the case study method. With the concept of farming and farm acceptance and income. So this research uses income analysis and $R$ / C ratio analysis (Return Ana Cost Ratio), namely the comparison analysis and farm acceptance. The data used in the study were obtained from direct interviews with farmers who are members of the Wargi Saluyu farmer group in Ciparay Village and added with other supporting data that can support from literature and literature studies. The results of this study indicate the Ciherang variety rice farming in Ciparay Village, Ciparay District, Bandung Regency has a total cost of IDR 17,379,500.00 per hectare and revenue of IDR 34,742,000.00 per hectare which generates an income of IDR 17,362,500.00 per hectare. in one growing season. And the $R / C$ ratio of Ciherang variety rice farming in Ciparay Village, Ciparay District, Bandung Regency is 1.9, which means that ciherang variety of rice farming in Ciparay Village, Ciparay District, Bandung Regency is profitable or feasible to be cultivated.
\end{abstract}

Keywords: farm income, farming feasibility, rice.

ABSTRAK
Penelitian ini dilakukan untuk menganalisis tingkat pendapatan dan efisiensi dari usahatani padi di kelompok tani
Wargi Saluyu Desa Ciparay. Adapun varietas padi yang yang menjadi fokus penelitian ini adalah jenis padi varietas
ciherang. Metode yang digunakan dalam penelitian ini adalah metode studi kasus. Dengan konsep usahatani dan
penerimaan dan pendapatan usahatani. Sehingga penelitian ini menggunakan analisis pendapatan dan analisis R/C
ratio (Return Ana Cost Ratio) yaitu analisis perbandingan dan penerimaan usahatani. Data yang digunakan dalam
penelitian didapatkan dari hasil wawancara langsung kepada petani yang tergabung dalam kelompok tani Wargi
Saluyu Desa Ciparay dan ditambahkan dengan data pendukung lain yang dapat menunjang dari studi literatur dan
pustaka. Hasil dari penelitian ini menunjukkan usahatani padi Varietas Ciherang di Desa Ciparay Kecamatan Ciparay
Kabupaten Bandung mempunyai total biaya sebesar Rp 17.379.500,00 per hektar dan penerimaan Rp $34.742 .000,00$
per hektar yang menghasilkan pendapatan sebesar Rp $17.362 .500,00$ per hektar dalam satu kali musim tanam. Dan
R/C Ratio usahatani padi Varietas Ciherang di Desa Ciparay Kecamatan Ciparay Kabupaten Bandung adalah sebesar 
1,9 yang berarti usahatani padi varietas ciherang di desa Ciparay kecamatan Ciparay kabupaten Bandung menguntungkan atau layak untuk diusahakan.

Kata kunci: kelayakan usahatani, padi, pendapatan usahatani.

\section{PENDAHULUAN}

Usahatani memegang peranan penting terhadap ketersediaan pangan di Indonesia. Salah satu komoditas yang berperan dalam ketersediaan pangan tersebut adalah padi. Usahatani padi dapat menghasilkan beras yang merupakan makanan pokok untuk dikonsumsi oleh sebagian besar penduduk Indonesia. Kecenderungan konsumsi beras yang meningkat di Indonesia, maka produksi beras juga harus ditingkatkan agar tercapainya keseimbangan antara permintaan dan penawaran beras. Upaya tersebut dilakukan untuk memenuhi kecukupan konsumsi maupun stock nasional yang sesuai persyaratan operasional logistik. Salah satu komoditas yang berperan dalam ketersediaan pangan tersebut adalah padi. Ketersediaan bahan pangan (beras) dalam negeri yang belum mencukupi dapat menjadi masalah nasional bagi Indonesia. Beras yang diperoleh petani berasal dari butiran-butiran padi (Firardhi et al., 2015).

Padi tidak hanya berperan penting sebagai makanan pokok dan makanan pangan, tetapi juga merupakan sumber perekonomian sebagian besar masyarakat Indonesia yang tinggal di pedesaan. Apabila terjadi kekurangan produksi padi, maka akan berpengaruh terhadap berbagai jenis aspek kehidupan masyarakat termasuk sosial, ekonomi, bahkan politik. Sebagai salah satu alat untuk mengevaluasi sistem ketersediaan beras di tingkat nasional secara kuantitatif dan cepat (Nurmalina, 2008).

Oleh sebab itu, dalam upaya peningkatan produksi padi untuk memenuhi kebutuhan pangan yang terus meningkat seiring dengan meningkatnya jumlah penduduk tentu perlu mendapat perhatian utama dari pemerintah dalam pembangunan pertanian (Mulyati and Sumarna, 2019).
Menurut Cahyaningrom (2012), saat ini tersedia berbagai varietas unggul baru yang dapat dipilih sesuai dengan kondisi wilayah, seperti produktivitas tinggi, dan rasa nasi yang enak, salah satunya adalah varietas Ciherang. Varietas Ciherang adalah hasil persilangan antara varietas IR 64 dengan varietas/galur lain. Sebagian sifat IR 64 juga dimiliki oleh Ciherang, termasuk hasil dan mutu berasnya yang tinggi.

Menurut Badan Litbang Pertanian (2015) (2015), Padi ciherang memiliki keunggulan dalam hal umur tanam yang pendek yaitu antara 115-125 hari, hasil produksi yang cukup tinggi yaitu dengan hasil mencapai 5-8,5 ton/ha (dengan perlakuan yang sama), anakan produktif yang banyak, tahan terhadap hama dan penyakit, cocok ditanam pada saat musim hujan dan kemarau, tahan terhadap hama wereng coklat biotipe 2 dan biotipe 3, tahan terhadap hawar daun bakteri Strain III dan IV, lebih tahan saat tergenang air (saat musim hujan tinggi), memiliki postur nasi yang pulen, serta rasa nasi yang enak.

Badan Pusat Statistik (2019), mencatat Provinsi Jawa Barat merupakan salah satu provinsi penghasil padi di Indonesia dengan jumlah produksi 9,08 juta ton per tahun. Desa Cipray Kecamatan Ciparay Kabupaten Bandung merupakan salah satu desa yang berada di Jawa Barat yang sebagian besar penduduknya adalah petani, sebagian besar petani di Desa Ciparay Kecamatan Ciparay Kabupaten Bandung mengusahakan padi varietas Ciherang. Desa Ciparay Kecamatan Ciparay Kabupaten Bandung memiliki potensi cukup besar dalam bidang pertanian karena memiliki daerah yang cukup strategis salah satunya dekat dengan aliran sungai sehingga memudahkan petani mendapatkan air pada saat musim kemarau.

Tingkat pendapatan yang diterima petani bergantung pada berbagai faktor yang 
mempengaruhi produktivitas lahan seperti contoh faktor cuaca, penggunaan bibit unggul dan lainlain. Beberapa indikator menunjukkan bahwa di beberapa daerah banyak petani yang belum menikmati hasil jerih payahnya secara memadai. Untuk itu perlu dilakukan penelitian pada usahatani padi varietas Ciherang, mengenai sejauh mana keberhasilan petani yang mengusahakan varietas padi Ciherang.

\section{METODE PENELITIAN}

Metode yang digunakan dalam penelitian ini adalah metode studi kasus. Studi kasus yang dilakukan pada penelitian ini adalah menganalisis pendapatan dan kelayakan finansial secara rinci pada Kelompok Tani Wargi Saluyu di Desa Ciparay Kecamatan Ciparay Kabupaten Bandung yang mengusahakan padi Varietas Ciherang selama kurun waktu tertentu.

\section{Konsep Usahatani}

Ilmu usaha tani adalah ilmu yang mempelajari bagaimana seseorang mengusahakan dan mengkoordinir faktor-faktor produksi berupa lahan dan alam sekitarnya sebagai modal sehingga memberikan manfaat yang sebaik-baiknya. Sebagai ilmu pengetahuan, ilmu usahatani merupakan ilmu yang mempelajari cara-cara petani menentukan, mengorganisasikan penggunaan faktor-faktor produksi seefektif dan seefisien mungkin, sehingga usaha tersebut memberikan pendapatan semaksimal mungkin (Irawati, 2019).

\section{Konsep Penerimaan dan Pendapatan Usahatani}

Penerimaan usahatani adalah perkalian antara produksi yang diperoleh dengan harga jual. Semakin banyak jumlah produk yang dihasilkan maupun semakin tinggi harga per unit produksi yang bersangkutan, maka penerimaan total yang diterima produsen akan semakin besar. Sebaliknya jika produk yang dihasilkan sedikit dan harganya rendah maka penerimaan total yang diterima produsen semakin kecil (Wahyuni, 2019).

Penerimaan usahatani padi Astuti (2013), dihitung dengan rumus:

\section{$\mathbf{T R}=\mathbf{P} \times \mathbf{Y}$}

Keterangan:

$$
\begin{array}{ll}
\mathrm{TR} & =\text { Penerimaan total } \\
\mathrm{P} & =\text { Harga produk } \\
\mathrm{Y} & =\text { Jumlah produk yang dihasilkan }
\end{array}
$$

Menurut Arfah et al., (2020), pendapatan usahatani merupakan selisih biaya yang dikeluarkan dan penerimaan yang diperoleh. Besarnya pendapatan yang diterima merupakan balas jasa untuk tenaga kerja, modal kerja keluarga yang dipakai dan pengelolaan yang dilakukan oleh seluruh anggota keluarga. Bentuk dan jumlah pendapatan memiliki fungsi yang sama, yaitu untuk memenuhi keperluan seharihari dan memberikan kepuasan petani agar dapat melanjutkan kegiatannya.

Menurut Arfah et al., (2020), analisis pendapatan bertujuan untuk mengetahui tingkat pendapatan usahatani padi, untuk mengetahui jumlah pendapatan dari usaha tani padi dengan menggunakan analisis, sebagai berikut:

$$
\boldsymbol{\pi}=\mathbf{T R}-\mathbf{T C}
$$

$$
\begin{aligned}
& \text { Keterangan: } \\
& \Pi \quad=\text { Pendapatan Usaha Tani Padi (Rp/ha/Musim) } \\
& \mathrm{TR}=\text { Total Revenue (Penerimaan Total) } \\
& \quad \text { (Rp/ha/Musim) } \\
& \mathrm{TC}=\text { Total Cost (biaya Total) }(\mathrm{Rp} / \mathrm{ha} / \text { Musim) }
\end{aligned}
$$

Sedangkan efisiensi usahatani padi dihitung dengan rumus:

$$
\text { Efisiensi }=\mathbf{R} / \mathrm{C}
$$

\section{Keterangan:}

$$
\begin{array}{ll}
\mathrm{R} & =\text { Total Penerimaan Usahatani Padi } \\
\mathrm{C} & =\text { Total Biaya Usahatani Padi. }
\end{array}
$$

Menurut (Saragi and Panjaitan, 2020), $\mathrm{R} / \mathrm{C}$ adalah perbandingan antara penerimaan dengan biaya total, dinyatakan dengan menggunakan rumus: 


$$
\mathbf{R} / \mathbf{C}=\frac{\text { Penerimaan Total }}{\text { Biaya Total }}
$$

Penerimaan Total/Biaya Total

Dari hasil analisis tersebut dapat dilihat berapa jumlah penerimaan yang akan diperoleh petani dari setiap rupiah yang dikeluarkan petani dalam usahatani cabai merah tersebut, dengan ketentuan sebagai berikut:

a. R/C > 1, maka usahatani padi tersebut menguntungkan, sehingga usaha tersebut layak untuk diusahakan.

b. $\quad \mathrm{R} / \mathrm{C}=1$, maka usahatani padi tersebut sama rata, sehingga usaha tersebut tidak untung tidak rugi.

c. $\mathrm{R} / \mathrm{C}<1$, maka usahatani padi tersebut rugi, sehingga usaha tersebut tidak layak diusahakan.

\section{Biaya Usahatani}

Menurut Astuti (2013), biaya adalah nilai korbanan yang dikeluarkan untuk memperoleh hasil. Menurut kerangka waktunya, biaya dapat dibedakan menjadi biaya jangka pendek, dan biaya jangka panjang. Biaya jangka pendek terdiri dari biaya tetap, dan biaya variabel, sedangkan dalam jangka panjang semua biaya dianggap/diperhitungkan sebagai biaya variabel. Biaya usahatani akan dipengaruhi oleh jumlah pemakaian input, harga dari input, tenaga kerja, upah tenaga kerja, dan intensitas pengelolaan usahatani.

Biaya total merupakan keseluruhan jumlah biaya produksi yang dikeluarkan, yaitu merupakan penjumlahan dari biaya tetap dan biaya variabel (Wahyuni, 2019), dapat ditulis sebagai berikut:

$$
\mathbf{T C}=\mathbf{T F C}+\mathbf{T V C}
$$

Keterangan:

$\mathrm{TC}=$ Biaya Total

TFC $=$ Total Biaya Tetap

$\mathrm{TVC}=$ Total Biaya Vaiabel

\section{HASIL DAN PEMBAHASAN}

\section{A. Biaya Usahatani Padi Varietas Ciherang}

Biaya usahatani padi varietas ciherang adalah seluruh komponen biaya yang dikeluarkan petani dalam bentuk tunai dan biaya yang diperhitungkan untuk melakukan usahataninya selama proses produksi dalam satu kali musim tanam pada kelompok tani Wargi Saluyu Desa Ciparay yang dikonversikan ke hektar yang menggunakan sistem tanam tegel (jarak tanam $22 \mathrm{~cm} \times 22 \mathrm{~cm}$ ). Biaya tunai (biaya tetap) dalam penelitian ini meliputi benih, pupuk urea, pupuk $\mathrm{KCl}$, pupuk NPK, tenaga kerja luar keluarga dan pajak lahan. Pajak lahan termasuk kedalam biaya tunai untuk petani yang menggarapnya sendiri (lahan milik sendiri) sedangkan petani penggarap tidak membayar pajak.

Biaya diperhitungkan (biaya variabel) yang dikeluarkan oleh petani meliputi sewa lahan, dan penyusutan peralatan. Sewa lahan merupakan komponen biaya diperhitungkan bagi petani yang menggarap lahan sendiri ataupun bagi petani penggarap, hal ini karena petani penggarap tidak mengeluarkan uang tunai untuk menyewa lahan tetapi dengan cara bagi hasil. Sewa lahan termasuk kedalam biaya diperhitungkan karena lahan mempunyai nilai ekonomis yang terus meningkat dibandingkan sarana lainnya. Rincian biaya tetap dan biaya variabel untuk usahatani padi varietas ciherang pada Kelompok Tani Wargi Saluyu Desa Ciparay Kecamatan Ciparay Kabupaten Bandung dapat di lihat pada Tabel 1 dan 2 berikut.

Pada Tabel 1 menunjukan bahwa sewa lahan merupakan bahan yang diperhitungkan bagi petani yang menggarap lahan sendiri (pemilik lahan) ataupun bagi petani penggarap. Tingkat penyusutan terbesar berada pada alat Hand Sprayer dengan biaya penyusutan per musim tanam sebesar $\mathrm{Rp}$ 79.000,00. Kondisi ini dipengaruhi oleh harga dan umur teknis alat tersebut, dimana harga beli Hand Sprayer 
merupakan harga tertinggi dari beberapa alat yang digunakan.

Tabel 1. Rincian Biaya Tetap Usahatani Padi Varietas Ciherang pada Kelompok Tani Wargi Saluyu Desa Ciparay

\begin{tabular}{|c|c|c|c|c|c|c|c|}
\hline \multirow{2}{*}{ No } & \multirow{2}{*}{ Komponen } & \multirow{2}{*}{$\begin{array}{c}\text { Jumlah } \\
\text { (Unit) }\end{array}$} & \multirow{2}{*}{$\begin{array}{c}\begin{array}{c}\text { Harga } \\
\text { Beli }\end{array} \\
\text { (Unit) }\end{array}$} & \multirow{2}{*}{$\begin{array}{c}\begin{array}{c}\text { Umur } \\
\text { Teknis }\end{array} \\
\text { (Tahun) }\end{array}$} & \multirow{2}{*}{$\begin{array}{c}\text { Jumlah } \\
\text { (Rp) }\end{array}$} & \multicolumn{2}{|c|}{ Biaya Penyusutan } \\
\hline & & & & & & (Rp/Thn) & (Rp/Musim) \\
\hline 1 & Sewa Lahan & $\begin{array}{l}1 \\
\text { Hektar }\end{array}$ & & & & 10.000 .000 & $3.333 .500,00$ \\
\hline \multirow[t]{7}{*}{2} & Penyusutan & & & & & & \\
\hline & Cangkul & 4 & $75.000,00$ & 5 & 300.000 & 60.000 & $20.000,00$ \\
\hline & Golok & 1 & $55.000,00$ & 5 & 55.000 & 11.000 & $4.000,00$ \\
\hline & Arit & 6 & $60.000,00$ & 5 & 360.000 & 72.000 & $24.000,00$ \\
\hline & $\begin{array}{l}\text { Hand } \\
\text { Sprayer }\end{array}$ & 3 & $550.000,00$ & 7 & 1.650 .000 & $236.000,00$ & $79.000,00$ \\
\hline & Jumlah & 14 & & & & $379.000,00$ & $107.127 .000,0077,78$ \\
\hline & $\begin{array}{l}\text { Total Biaya } \\
\text { Tetap }\end{array}$ & & & & & $10.379 .000,00$ & $3.460 .500,00$ \\
\hline
\end{tabular}

(Sumber: data Primer, 2020)

Tabel 2. Rincian Rata-rata Biaya Variabel Usahatani Padi Varietas Ciherang Pada Kelompok Tani Wargi Saluyu Desa Ciparay

\begin{tabular}{|c|c|c|c|c|c|}
\hline No & Komponen & $\begin{array}{l}\text { Jumlah } \\
\text { Fisik }\end{array}$ & Satuan & $\begin{array}{l}\text { Harga Satua } \\
\qquad(\mathrm{Rp})\end{array}$ & Biaya (Rp) \\
\hline 1 & Benih & 25,53 & $\mathrm{Kg}$ & 24.000 & $638.500,00$ \\
\hline 2 & Karung & 109,98 & & 2.000 & $219.000,00$ \\
\hline \multirow[t]{5}{*}{3} & Pupuk Kimia & & & & \\
\hline & Urea & 225,3 & $\mathrm{Kg}$ & 7.000 & $1.557 .500,00$ \\
\hline & $\mathrm{KCl}$ & 69,81 & $\mathrm{Kg}$ & 9.000 & $628.500,00$ \\
\hline & NPK & 121,25 & $\mathrm{Kg}$ & 12.000 & $1.455 .000,00$ \\
\hline & Jumlah Biaya Pupuk & & & & $3.661 .000,00$ \\
\hline \multirow[t]{4}{*}{4} & Pestisida & & & & \\
\hline & Fungisida & $1.000,10$ & $\mathrm{ml}$ & $25.000 / 100 \mathrm{ml}$ & $250.000,00$ \\
\hline & Insektisida & 145,86 & $\mathrm{ml}$ & $100.000 / 50 \mathrm{ml}$ & $292.000,00$ \\
\hline & Moluskisida & 486,14 & $\mathrm{ml}$ & $25.000 / 100 \mathrm{ml}$ & $121.500,00$ \\
\hline \multirow[t]{4}{*}{5} & $\begin{array}{l}\text { Jumlah Biaya Pestisida } \\
\text { Tenaga Kerja Luar } \\
\text { Keluarga }\end{array}$ & & & & $663.500,00$ \\
\hline & Pembajakan & 1 & Orang/ha & 1.400 .000 & $1.400 .000,00$ \\
\hline & Pembuatan Galengan & 11,56 & HOK & 70.000 & $809.500,00$ \\
\hline & Pembibitan & 4,21 & HOK & 70.000 & $295.000,00$ \\
\hline
\end{tabular}




\begin{tabular}{|c|c|c|c|c|c|}
\hline No & Komponen & $\begin{array}{c}\text { Jumlah } \\
\text { Fisik }\end{array}$ & Satuan & $\begin{array}{c}\text { Harga Satua } \\
\quad(\mathrm{Rp})\end{array}$ & Biaya (Rp) \\
\hline \multirow{16}{*}{6} & Penanaman & 17,93 & HOK & 50.000 & $896.000,00$ \\
\hline & Pemupukan & 5,73 & HOK & 70.000 & $401.500,00$ \\
\hline & Penyiangan & 28,6 & HOK & 50.000 & $1.430 .000,00$ \\
\hline & Pengendalian HPT & 8,39 & HOK & 70.000 & $587.500,00$ \\
\hline & Pemanenan & 25,04 & HOK & 70.000 & $1.753 .000,00$ \\
\hline & Jumlah Tenaga Kerja & 102,46 & & & $7.572 .500,00$ \\
\hline & Tenaga Kerja Dalam Keluarga & & & & \\
\hline & Pembuatan Galengan & 2,23 & HOK & 70.000 & $156.500,00$ \\
\hline & Pembibitan & 1,31 & HOK & 70.000 & $92.000,00$ \\
\hline & Penanaman & 2,6 & HOK & 50.000 & $130.000,00$ \\
\hline & Pemupukan & 2,99 & HOK & 70.000 & $209.500,00$ \\
\hline & Penyiangan & 3,73 & HOK & 50.000 & $186.500,00$ \\
\hline & Pengendalian HPT & 2,66 & HOK & 70.000 & $186.500,00$ \\
\hline & Pemanenan & 3,48 & HOK & 70.000 & $203.000,00$ \\
\hline & Jumlah Tenaga Kerja & 18,42 & & & $1.164 .000,00$ \\
\hline & Total Biaya Variabel & & & & 13.919.000,00 \\
\hline
\end{tabular}

(Sumber: data primer, 2020)

Pada Tabel 2 diperoleh data bahwa biaya kerja yang di butuhkan per hektar per usim tanam adalah 102,46 HOK. Pengendalian hama dan penyakit biasanya hanya dilakukan sekali selama musim tanam untuk mencegah adanya serangan hama, dimana hama dan penyakit yang biasa menyerang adalah Hama Merah, Tikus, dan Keong Mas. Komponen biaya pada usahatani padi sawah varietas ciherang dapat dilihat pada Tabel 3.

Tabel 3. Rata-Rata Biaya Total Usahatani Padi Varietas Ciherang Per Musim Tanam Per Hektar Pada Kelompok Tani Wargi Saluyu Desa Ciparay

\begin{tabular}{clrr}
\hline No & \multicolumn{1}{c}{ Keterangan } & Total Nilai (Rp) & Persentase (\%) \\
\hline A & Biaya Tetap & $3.333 .500,00$ & \\
1 & Sewa Lahan & $127.000,00$ & 19,18 \\
2 & Penyusutan Alat & $\mathbf{3 . 4 6 0 . 5 0 0 , 0 0}$ & 0,73 \\
& Total Biaya Tetap & & $\mathbf{1 9 , 9 1}$ \\
B & Biaya Variabel & & \\
1 & Sarana Produksi & $638.000,00$ & 3,67 \\
& Benih & $219.000,00$ & 1,26 \\
& Karung & $3.661 .000,00$ & 21,06 \\
& Pupuk Kimia & $663.500,00$ & 3,82 \\
& Pestisida & $7.573 .000,00$ & 43,58
\end{tabular}

50|Orchid A gri: Vol1, No 1, Bulan Februari Tahun 2021 


\begin{tabular}{clrr}
\hline \multirow{2}{*}{ No } & \multicolumn{1}{c}{ Keterangan } & Total Nilai (Rp) & Persentase (\%) \\
\hline 3 & Tenaga Kerja Dalam Keluarga & $1.164 .000,00$ & 6,7 \\
& Total Biaya Variabel & $\mathbf{1 3 . 9 1 9 . 0 0 0 , 0 0}$ & $\mathbf{8 0 , 0 9}$ \\
& Jumlah Total Biaya & $\mathbf{1 7 . 3 7 9 . 5 0 0 , 0 0}$ & $\mathbf{1 0 0}$ \\
\hline
\end{tabular}

(Sumber: data primer, 2020)

Pada Tabel 3 menunjukan bahwa persentase total biaya variabel lebih besar daripada biaya tetap dengan nilai 80,09 \% atau sebesar Rp 13.919.00,00 dari total biaya yaitu sebesar Rp 17.379.500,00 per hektar dalam satu kali musim tanam.

\section{B. Penerimaan Usahatani Padi Varietas Ciherang}

Penerimaan usahatani adalah jumlah total produk yang dijual berdasarkan pada harga yang berlaku di pasar total produksi rata-rata padi sawah varietas ciherang petani responden mencapai $6.812,10$ Kilogram per musim tanam per hektar. Harga jual padi pada saat panen adalah Rp 5.100,00 per kilogram, sehingga rata-rata penerimaan total usahatani padi yang diperoleh petani padi responden yaitu sebesar Rp 34.742.000,00 per hektar dalam satu kali musim tanam.

\section{Pendapatan Usahatani Padi Varietas Ciherang}

Nilai pendapatan usahatani padi ciherang diperoleh dari selisih penerimaan dan biaya usahatani. Adapun nilai penerimaan adalah sebesar Rp 34.742.000,00 dan total biaya usahatani padi adalah $\mathrm{Rp}$ 17.379.500,00 per hektar dalam satu kali musim tanam, sehingga pendapatan usahatani padi varietas ciherang yang diperoleh petani responden yaitu sebesar Rp 17.362.500,00 per hektar dalam satu kali musim tanam.

\section{Kelayakan (Nilai R/C Ratio) Usahatani Padi Varietas Ciherang}

Hasil perhitungan usahatani padi varietas ciherang di desa ciparay untuk analisa $\mathrm{R} / \mathrm{C}$ ratio diperoleh 1,9. Nilai ini memiliki arti bahwa setiap pengeluaran sebesar Rp 1- akan menghasilkan penerimaan sebesar Rp 1,9. Nilai $\mathrm{R} / \mathrm{C}$ ratio lebih dari satu $(\mathrm{R} / \mathrm{C}>1)$ menunjukkan bahwa usahatani tersebut mampu memberikan keuntungan 1,9 kali dari biaya yang dikeluarkan. Hal ini menunjukkan bahwa usahatani padi varietas ciherang di desa ciparay menguntungkan. Secara rinci nilai $R / C$ ratio usahatani padi varietas ciherang di desa ciparay dapat dilihat pada Tabel 4.

Tabel 4. Analisa Nilai R/C Ratio Usahatani Padi Varietas Ciherang Per Musim Tanam Per Hektar Pada Kelompok Tani Wargi Saluyu Desa Ciparay

\begin{tabular}{lll}
\hline No & Komponen & Nilai (Rp) \\
\hline A & Biaya Tetap & $3.460 .500,00$ \\
B & Biaya Variable & $13.919 .500,00$ \\
C & Biaya Total (A+B) & $17.919 .500,00$ \\
D & Hasil Produksi (Kg) & $6.812,10$ \\
E & Harga per Kilogram & 5.100 \\
F & Penerimaan Total (D x E) & $34.742 .000,00$ \\
G & Pendapatan Total (F - C) & $17.362 .500,00$ \\
H & R/C Ration (F/C) & 1,90 \\
\hline
\end{tabular}

(Sumber: data primer, 2020)

\section{KESIMPULAN DAN SARAN}

\section{Kesimpulan}

Berdasarkan hasil penelitian yang dilakukan, maka dapat dikemukakan kesimpulan yaitu usahatani padi Varietas Ciherang di Desa Ciparay Kecamatan Ciparay Kabupaten Bandung mempunyai total biaya sebesar Rp 17.379.500,00 per hektar dan penerimaan Rp 34.742.000,00 per 
hektar yang menghasilkan pendapatan sebesar Rp 17.362.500,00 per hektar dalam satu kali musim tanam. Dan R/C Ratio usahatani padi Varietas Ciherang di Desa Ciparay Kecamatan Ciparay Kabupaten Bandung adalah sebesar 1,9 yang berarti usahatani padi varietas ciherang di desa Ciparay kecamatan Ciparay kabupaten Bandung menguntungkan atau layak untuk diusahakan.

\section{Saran}

Berdasarkan hasil penelitian yang diperoleh, maka dapat dikemukakan saran sebagai berikut:

1. Petani di Desa Ciparay Kecamatan Ciparay Kabupaten Bandung dalam menjalankan usahatani padi varietas ciherang sebaiknya menekan atau mengurangi biaya produksi khususnya biaya produksi tenaga kerja luar keluarga dengan salah satu cara dapat mengendalikan hama dengan musuh alami dari hama tersebut sehingga pendapatan usahatani yang diperoleh dapat meningkat.

2. Petani di Desa Ciparay Kecamatan Ciparay Kabupaten Bandung diharapkan dapat mencoba hal-hal serta inovasi baru dari hasil penyuluhan pemerintah seperti contohnya dapat mengelola kotoran hewan ternak menjadi pupuk sehingga dapat digunakan untuk menggantikan pupuk kimia sehingga dapat menekan pengeluaran untuk pupuk se maksimal mungkin.

3. Petani di Desa Ciparay Kecamatan Ciparay Kabupaten Bandung diharapkan dapat meningkatkan hasil produksi dan dapat mengantisipasi serangan hama dan penyakit pada tanaman padi sehingga hasil produksi yang diperoleh tidak mengalami penurunan yang berakibat pada pendapatan yang diperoleh petani.

\section{DAFTAR PUSTAKA}

Arfah, D., D. Rochdiani, and A.Y. Isyanto. 2020. Analisis Biaya, Pendapatan dan R/C Pada Usahatani Kacang Hijau (Studi Kasus di
Desa Kertajaya Kecamatan Mangunjaya Kabupaten Pangandaran). J. Ilm. Mhs. Agroinfo Galuh 7(1): 177. doi: 10.25157/jimag.v7i1.2574.

Astuti. 2013. Analisis Pendapatan Usaha Tani

Padi Sawah (Oriza sativa L.) Di Kecamatan Kaway XVI Kabupaten Aceh Barat. http://repository.utu.ac.id/id/eprint/530.

Badan Litbang Pertanian. 2015. Varietas Ciherang. Kementeri. Pertan. http://www.litbang.pertanian.go.id/varietas /130/.

Badan Pusat Statistik. 2019. Produksi Padi Menurut Provinsi (ton). https://www.bps.go.id/linkTableDinamis/vi ew/id/865.

Cahyaningrom, E. 2012. Faktor-Faktor Penentu Petani Dalam Adopsi Budidaya Padi Varietas Ciherang Di Desa Pucangan Kecamatan Kartasura Kabupaten Sukoharjo. 1 . https://www.google.com/url?sa=t\&rct=j\&q $=\&$ esrc $=$ s $\&$ source $=$ web $\& c d=\&$ ved $=2 \mathrm{ahU}$

KEwiEk-

2QgsXuAhXO7XMBHSuBCxwQFjAAeg QIAhAC\&url=https\%3A\%2F\%2Fdigilib.u ns.ac.id\%2Fdokumen\%2Fdownload\%2F24 282\%2FNTE0NDA\%3D\%2FFaktorfaktor-penentu-petani-dalam-adopsibudidaya-padi-variet.

Firardhi, F., T. Hasanuddin, and S. Sadar. 2015. Persepsi Terhadap Usahatani Padi Varietas Cimalaya Muncu dan Ciherang Di Kecamatan Palas Kabupaten Lampung Selatan. JIIA 3(1): 1-9. https://media.neliti.com/media/publications /13328-ID-persepsi-petani-terhadapusahatani-padi-varietas-cilamaya-munculdan-ciherang-di.pdf.

Irawati. 2019. Analisis Pendapatan Petani Padi Sawah Di Desa Kuala Mulia Kecamatan Kuala Cenaku Kabupaten Indragiri Hulu. J. Manaj. dan Bisnis 8(2): 342-353. doi: https://doi.org/10.34006/jmbi.v8i1.63. 
Mulyati, N.S., and P. Sumarna. 2019. Analisa Usahatani Padi Ketan (Oryza sativa glutinosa) (Studi Kasus di Kelompok Tani Sri Rahayu Desa Margamulya Kecamatan Bongas Kabupaten Indramayu. PASPALUM J. Ilm. Pertan. 7(2): 24-33. doi:

http://dx.doi.org/10.35138/paspalum.v7i2.1 48.

Nurmalina, R. 2008. Keberlanjutan Sistem Ketersediaan Beras Nasional: Pendekatan Teknik Ordinasi Rap-Rice Dengan Metoda Multidimensional Scaling (Mds). J. Agribisnis dan Ekon. Pertan. 2(2): 65-88. https://media.neliti.com/media/publications
19379-ID-keberlanjutan-sistemketersediaan-beras-nasional-pendekatanteknik-ordinasi-rap.pdf.

Saragi, F.H., and F.A.B. Panjaitan. 2020. Faktorfaktor yang Mempengaruhi Pendapatan Rumah Tangga Tani Padi Ciherang Di Desa Tebing Tinggi Kabupaten Serdang Bedagai. J. Agrica 9(2): 101. doi: 10.31289/agrica.v9i2.486.

Wahyuni, S. 2019. Analisis Pendapatan Usahatani Alpukat Di Kecamatan Banding Agung Kabupaten Ogan Komering Ulu Selatan. JASEP 5(1): 69-73. https://journal.unbara.ac.id/index.php/jsp/a rticle/view/507/383. 